\title{
Mortality Trends from Cardiovascular Diseases in the State of Bahia, Brazil, between 2000 and 2015
}

\author{
Yana Mendonça Nascimento ${ }^{\circledR}$ and Adriana Lopes Latado ${ }^{(0}$ \\ Universidade Federal da Bahia - Faculdade de Medicina de Bahia, Salvador, BA - Brazil.
}

\section{Abstract}

Background: Mortality from cardiovascular diseases has reduced in Brazil in recent decades, but this phenomenon is not clear in the northeast region of the country.

Objectives: To describe the mortality trends from cardiovascular disease in Bahia from 2000-2015, in total population and by sex and age groups, and by specific causes (ischemic heart disease, cerebrovascular diseases, rheumatic heart disease and heart failure).

Methods: This was a time series study. Data were obtained from SIM-DATASUS and IBGE, and the 10th revision of the ICD used for disease classification. Mortality rates (per 100,000 inhabitants) were calculated from total cardiovascular disease and specific causes, by sex and age groups. Direct standardization was used to adjust for age, using the population of 2010 as reference. Linear regression models estimated percentage variation. The significance level of $5 \%$ was adopted.

Results: In Bahia, crude mortality rates from cardiovascular disease increased in the period; however, after standardization by age, mortality rates became stable for the total and female populations, with a slight reduction for the male population. An increase in mortality rates from cardiovascular disease was found in the elderly groups. For ischemic heart disease, a progressive increase in adjusted mortality rates was observed: $43 \%, 24 \%$ and $29 \%$ for the total, male, and female population, respectively. There was a progressive reduction in crude and agestandardized mortality rates from heart failure in all groups, a modest reduction in age-adjusted mortality rates from cerebrovascular diseases, and a slight reduction in age-standardized mortality rate from rheumatic heart disease, especially in the subgroup $<40$ years.

Conclusions: Mortality from cardiovascular disease in Bahia did not follow the decreasing trend of other Brazilian states, especially in relation to ischemic heart disease, which showed an increase in mortality rates. (Int J Cardiovasc Sci. 2020; 33(6):656-665)

Keywords: Cardiovascular Diseases/mortality; Heart Failure; Rheumatic Fever; Rheumatic; Rheumatic Heart Disease; Myocardial Ischemia; Cerebrovascular Disorders.

\section{Introduction}

In Brazil and worldwide, chronic non-communicable diseases are the health problem with the greatest impact on population morbidity and mortality. Cardiovascular diseases are the most frequent causes of death in many countries, accounting for $31.8 \%$ of deaths from chronic diseases in Brazil. ${ }^{1-4}$
From 1980 to 2012, there was a progressive decline in mortality rates from ischemic heart disease and cerebrovascular disease for the total population and by sex in Brazil. However, mortality from ischemic heart disease remained stable between 2007 and 2012, differently from the mortality rates from cerebrovascular disease, which maintained the downward trend. ${ }^{5}$ Despite these observations, the state of Bahia, as well as the

Mailing Address: Adriana Lopes Latado Braga

Rua Reitor Miguel Calmon, s/n, Postal Code: 40110-100, Canela, Salvador, Bahia - Brazil

E-mail: adrianalatado@cardiol.br 
northeast region of Brazil, showed a tendency of trend of increased mortality from cardiovascular disease in the same period. ${ }^{6}$

Despite the recognition of the relevance of cardiovascular diseases throughout the country and in the northeast region, there are few studies evaluating mortality trends in patients with cardiovascular diseases in the state of Bahia. Bahia is the largest and most populous state in the northeast region ${ }^{7}$ and the fourth most populous state of Brazil. Given the above, the present study aims to analyze the mortality trend from cardiovascular diseases in the state of Bahia by specific causes of death, by sex and age and in the total population between 2000 and 2015.

\section{Methods}

\section{Design and Data Source}

This is an ecological time series study, that analyzed trends in mortality from cardiovascular diseases in the state of Bahia, in the period between 2000 and 2015. Disease data were collected using their specific 10th Revision International Classification of Diseases (ICD 10) codes and analyzed separately or in combination, depending on the disease classification

Data on deaths were obtained from the Mortality Information System (SIM) of DATASUS (SUS Informatics Department), a public domain website, ${ }^{1}$ which covers vital statistics of the entire Brazilian population. Data on Bahia's population were obtained from the website of the Brazilian Institute of Geography and Statistics (IBGE)2, considering census years and population estimates of the analysis period.

For calculation of mortality rates, the total number of deaths by cause of death (numerator) was divided by the total population at risk (denominator) and then multiplied by 100,000 inhabitants (mortality rate/100,000 inhabitants). The calculations were made for the total population of Bahia State, and by sex groups. In addition, rates of mortality from all cardiovascular causes and specific components were calculated, defined as ischemic heart disease, cerebrovascular disease, rheumatic heart disease and heart failure, as described below in "defining diagnostic criteria". Mortality rates were also calculated by the age groups: $<40$ years, $40-59$ years, $60-69$ years, $70-79$ years and $\geq 80$ years. Data were stored in Excel ${ }^{\circledR}$ spreadsheets for further analysis.

\section{Defining Diagnostic Criteria}

1. ICD 10 codes for ischemic heart disease: angina pectoris (I20), acute myocardial infarction (I21), subsequent myocardial infarction (I22), other acute ischemic heart diseases (I24) and chronic ischemic heart disease (I25);

2. ICD 10 codes for cerebrovascular disease: subarachnoid hemorrhage (I60), intracerebral hemorrhage (I61), other nontraumatic intracranial hemorrhages (I62), cerebral infarction (I63), stroke, not specified as hemorrhagic or infarction (I64) and other cerebrovascular diseases (I67);

3. ICD 10 codes for rheumatic heart diseases: acute rheumatic fever with heart involvement (I01, I02), chronic rheumatic heart diseases (I05 to I09); and

4. ICD 10 Codes for heart failure: I50.

\section{Search Variables}

1. Death rate from total cardiovascular diseases and from ischemic heart disease, cerebrovascular disease, rheumatic heart disease and heart failure;

2. Cardiovascular disease mortality rate in total, male and female population, and according to age groups for: ischemic heart disease, cerebrovascular disease, rheumatic heart disease and heart failure; and

3. Standardized (age-adjusted) mortality rates for cardiovascular diseases and by specific cause group, for the total population and for male and female populations.

For the purposes of the present study, total cardiovascular disease was defined as the sum of deaths resulting from the four groupings of specific causes of death, as already reported.

\section{Statistical Analysis}

Data were presented as mortality rates per 100,000 inhabitants. In addition to crude mortality rates, a method of direct standardization of mortality rates was applied to adjust the results for variations in the age structure of the population in the evaluated period. The population of Bahia in 2010 was used as standard population for the adjustment. Simple linear regression models were used to assess the percentage of variation in mortality rates adjusted for age over the evaluated period, through the beta coefficients, and the level of significance adopted was $5 \%$. For this purpose, mortality rate was considered as a dependent variable and the year evaluated as an independent variable. All data and graph analyses were performed using the free " $R$ " software, and the Excel® program.

1 http://www2.datasus.gov.br/DATASUS/index.php?area=0205\&id=6937 2 https://www.ibge.gov.br/ 


\section{Results}

In Bahia, the mortality rate from cardiovascular diseases showed a progressive increase from 2000 to 2015, in the total population and in male and female groups (Table 1). For the total population, crude mortality rate from all cardiovascular diseases, considered as the sum of the specific causes described, was $65.85 / 100,000$ inhabitants in 2000, against 87.05/100,000 inhabitants in 2015 , which represented a relative increase of $32.2 \%$. With regard to the female population, the relative increase was $33.1 \%(63.37 / 100,000$ inhabitants in 2000 , to $84.28 / 100,000$ in 2015), similarly to what was observed for the male population (68.16/100,000 inhabitants in 2000 and $89.89 / 100,000$ inhabitants in 2015, an increase of $31.7 \%$ ).

Calculation of the age-standardized mortality rate showed that there was no variation in the study period for the total population $(77.6 / 100,000$ inhabitants in 2000 and 77.5/100,000 inhabitants in 2015). In the male population, there was a small relative reduction by $5.4 \%$, the rates remained stable between 2000 and 2015 in the female population (Figure 1). Analysis of mortality trends from cardiovascular disease in Bahia's total population by age group showed an increase in the rates in the oldest subgroup ( $>80$ years), with a slight reduction or no variation in the other age groups (Figure 2). The same pattern was observed for mortality from cardiovascular disease in the male population. In the female population, there was a trend towards more stable cardiovascular mortality rates over the period.

\section{Specific Cardiovascular Causes of Mortality}

\section{Ischemic Heart Disease}

In the study period, there was a progressive increase in crude and age-standardized mortality rates from ischemic heart disease. For the total, male and female populations, there was a relative increase by $75.5 \%$, $76.3 \%$ and $75.3 \%$, respectively, in the crude rates, and an increase by $43.0 \%, 24.4 \%$ and $29.2 \%$, respectively, for age-standardized mortality (Figure 3 ). In the analysis

Table 1 - Crude mortality rates (per 100,000 inhabitants) from cardiovascular diseases in total, male and female populations in the state of Bahia, Brazil, from 2000 to 2015

\begin{tabular}{|c|c|c|c|}
\hline & Total crude mortality rates & Crude mortality rates in men & Crude mortality rates in women \\
\hline 2000 & 65.85 & 68.16 & 63.37 \\
\hline 2001 & 70.01 & 72.43 & 67.45 \\
\hline 2002 & 71.66 & 74.34 & 68.91 \\
\hline 2003 & 69.74 & 71.86 & 67.59 \\
\hline 2004 & 70.19 & 72.47 & 67.87 \\
\hline 2005 & 66.68 & 67.60 & 65.74 \\
\hline 2006 & 85.25 & 88.14 & 82.35 \\
\hline 2007 & 80.47 & 83.27 & 77.65 \\
\hline 2008 & 80.00 & 82.02 & 77.96 \\
\hline 2009 & 80.76 & 82.64 & 78.88 \\
\hline 2010 & 82.34 & 85.83 & 78.86 \\
\hline 2011 & 82.78 & 86.46 & 79.13 \\
\hline 2012 & 83.92 & 85.76 & 82.11 \\
\hline 2013 & 82.25 & 86.29 & 78.26 \\
\hline 2014 & 85.18 & 90.41 & 80.03 \\
\hline 2015 & 87.05 & 89.89 & 84.28 \\
\hline
\end{tabular}




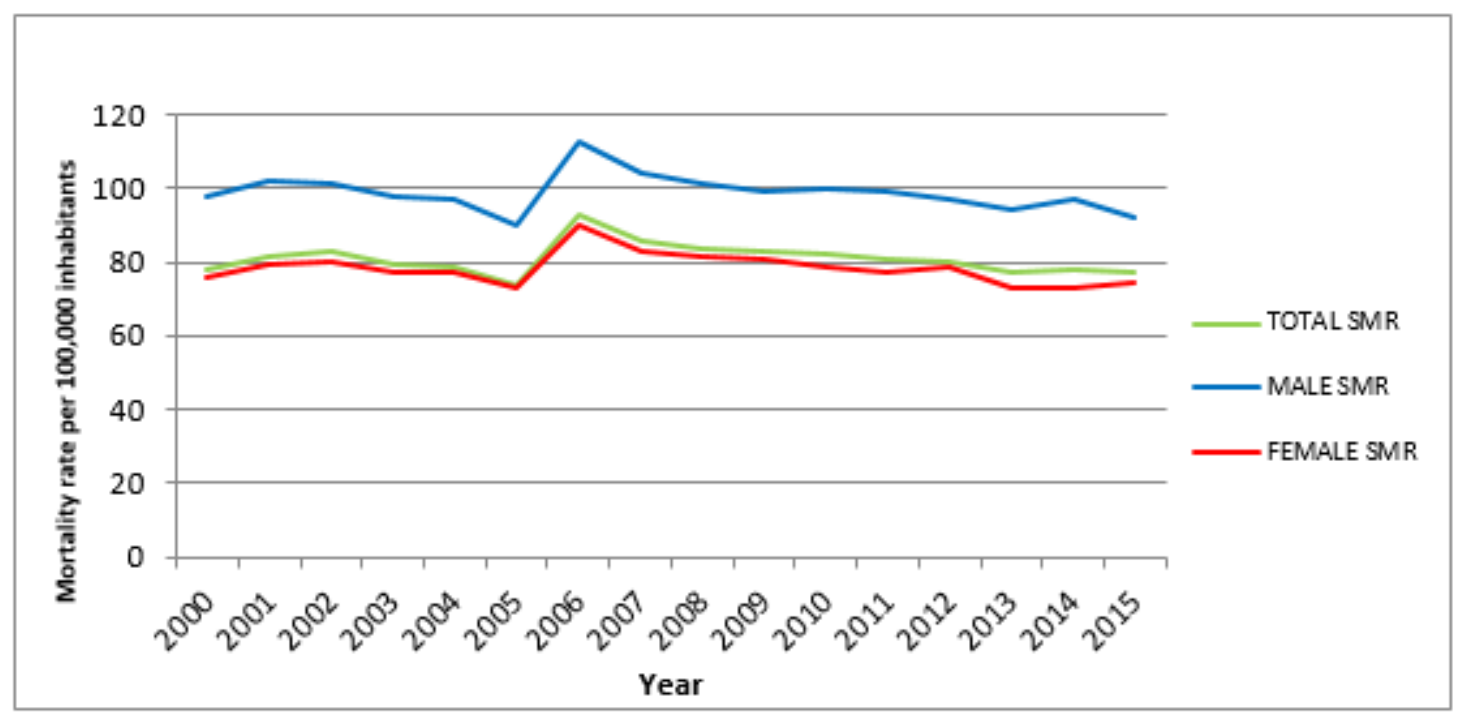

Figure 1- Age-standardized mortality curves from cardiovascular diseases in the population of Bahia, Brazil; SMR: standardized mortality rate

Source: DATASUS and IBGE

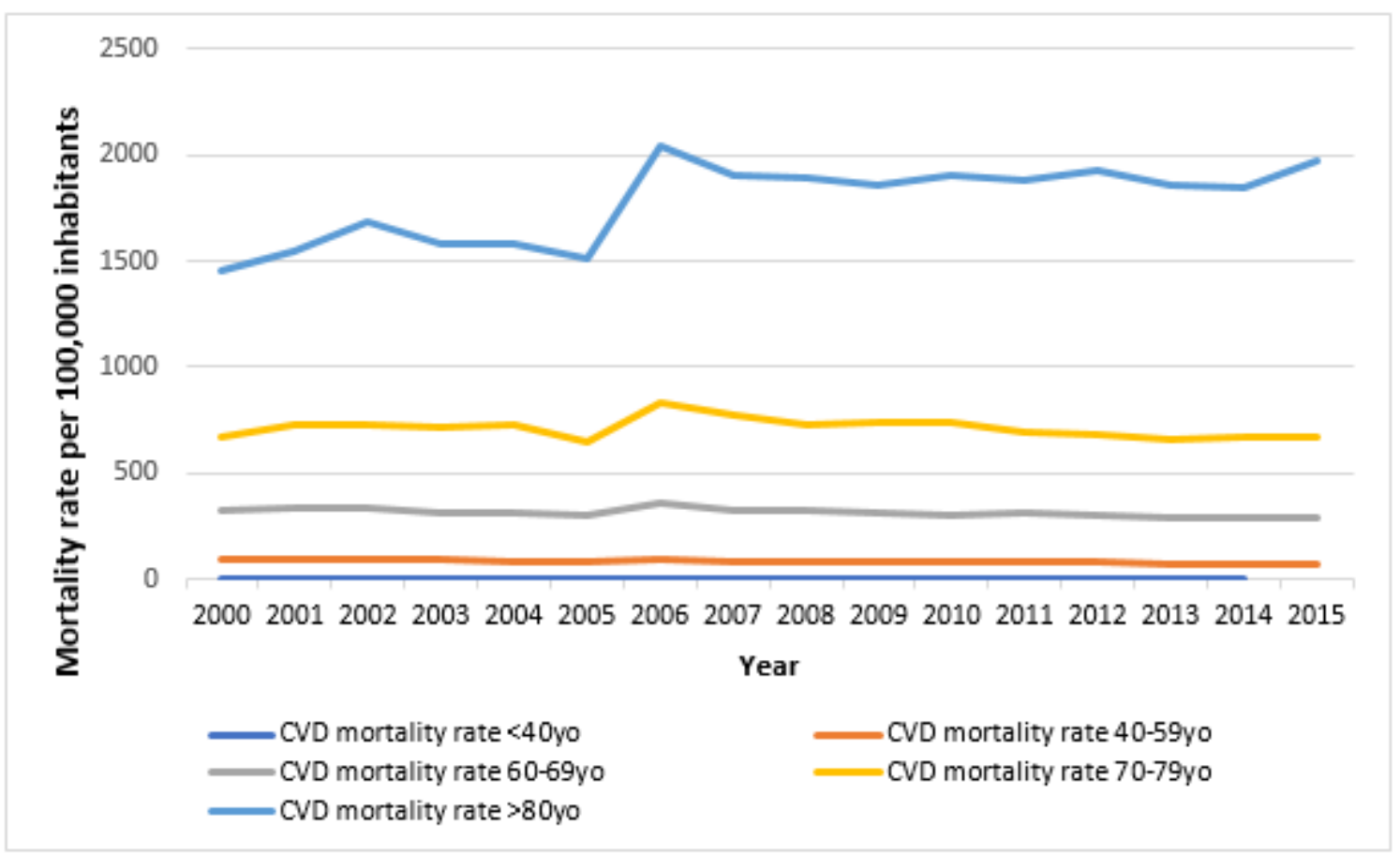

Figure 2 - Mortality curves from cardiovascular disease in the total population of Bahia, Brazil, by age groups Source: DATASUS and IBGE 
by age group, the mortality curves from ischemic heart disease progressively increased for individuals older than 60 years of age, in the total population and by sex. Linear regression models were developed, considering mortality as the outcome variable and the year as an independent variable, which showed an average annual increase in mortality rates of 0.59 (total population), 0.63 (male population) and 0.44 (female population).

\section{Heart Failure}

There was a progressive reduction in the crude and age-standardized mortality rates from heart failure in total, male and female populations. For the total population, the standardized rate declined from 16.67 to 10.96/100,000 inhabitants between 2000 and 2015, a decrease of $34.2 \%$. The female and male populations showed a similar trend, with reductions of $37 \%$ in the period (Figure 4). It was observed that the phenomenon occurred in a more homogeneous way, in the different age groups and for total and female populations. Men over 80 years of age exhibited great variability in the annual rates of heart failure mortality, with even an increase in the values between 2000 and 2015 (387.9 to $446.5 / 100,000$ inhabitants) (Figure 5). There was an average annual reduction in mortality rates for total, male and female populations $(0.40 ; 0.47 ; 0.43$, respectively).

\section{Cerebrovascular Disease}

For cerebrovascular diseases, there was a relative increase of $25.5 \%$ in the crude mortality rates from 2000 to 2015 in the total population. Among males, this increase was of $19.8 \%$ and, among females, of $31.2 \%$. A reduction in age-standardized mortality rates was observed, with a fall of $5.2 \%$ in total population, $14.8 \%$ among men and $2.5 \%$ in women (Figure 6). For mortality by age groups, data showed a modest progressive decrease in the rates for all the populations, except for the subgroup over 80 years of age, in which there was an apparent increase in the incidence of deaths from cerebrovascular disease. Ederly women had a higher number of deaths from cerebrovascular disease than men in the same age group.

\section{Rheumatic Heart Disease}

Regarding rheumatic disease, crude mortality rates remained stable in the period from 2000 to 2015 for the total population, and for the female and male populations. After standardization, it was possible to observe a trend towards a modest but progressive reduction in mortality from 2008 onwards for the total population, for men and women (Figure 7). Considering that the subgroup at the highest risk of dying from rheumatic disease was the youngest, we analyzed the trend of mortality in individuals under 40 years old, and found a downward trend for the total, male and female populations, despite the high variability of the data .

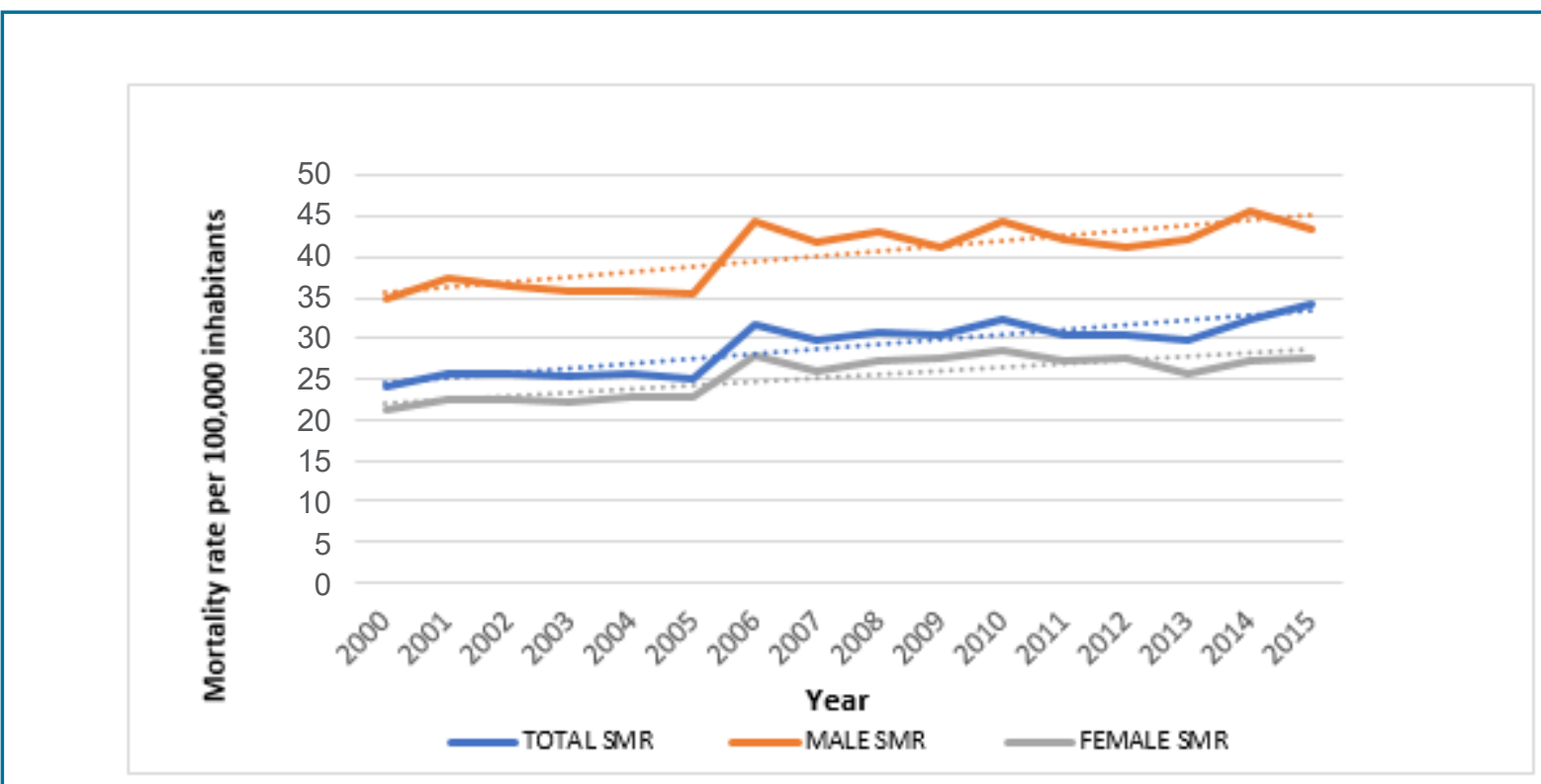

Figure 3 - Age-standardized mortality curves from ischemic heart disease in the population of Bahia, Brazil; SMR: standardized mortality rate

Source: DATASUS and IBGE 


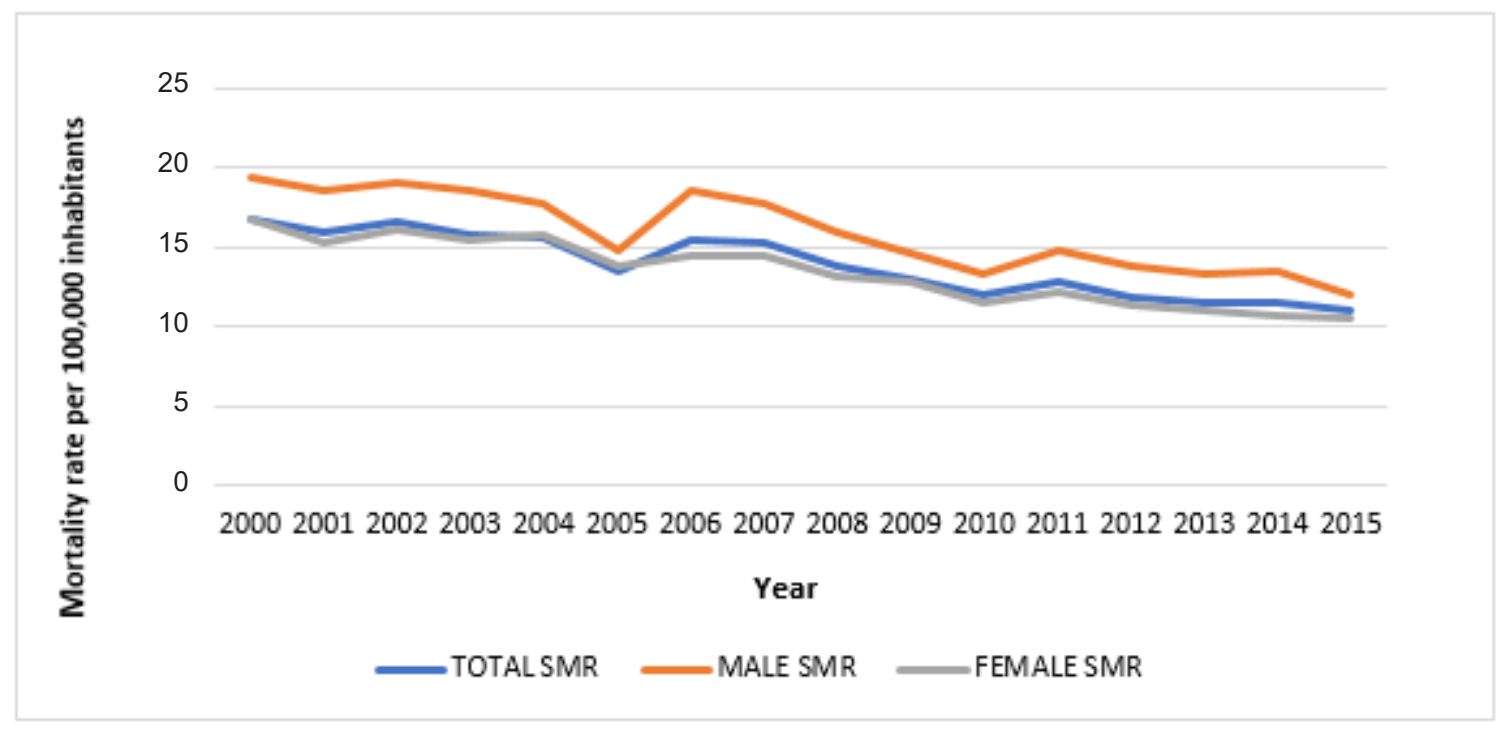

Figure 4 - Age-standardized mortality curves from heart failure in the population of Bahia State, Brazil; SMR: standardized mortality rate Source: DATASUS and IBGE

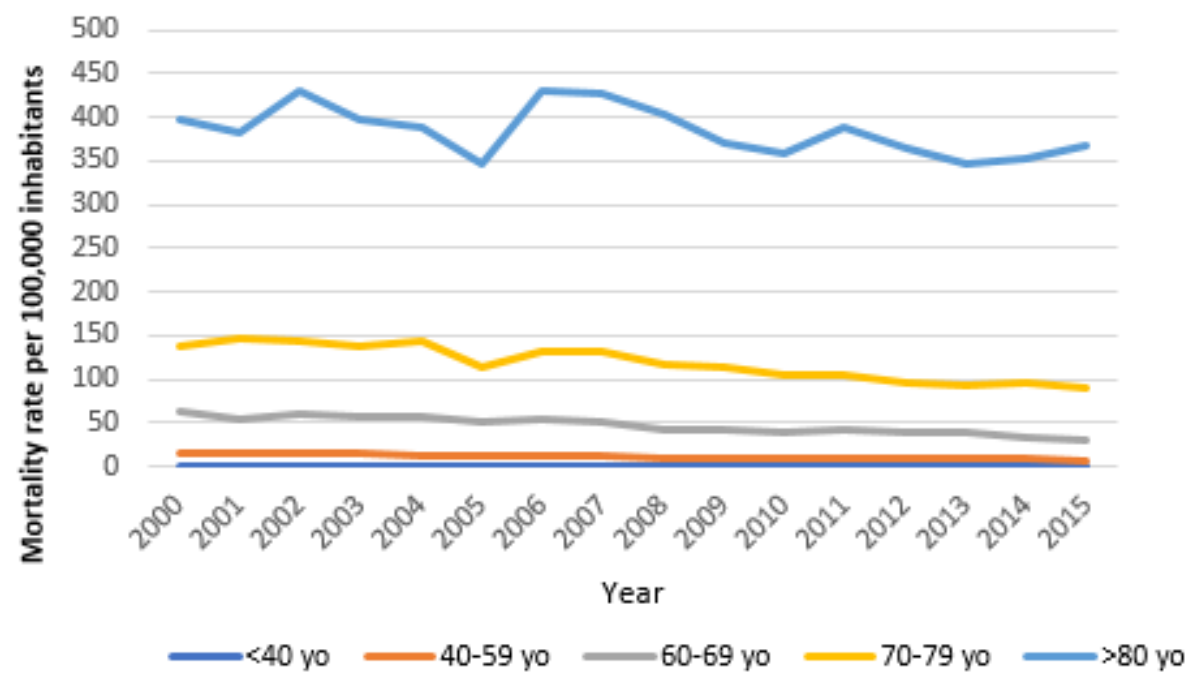

Figure 5 - Mortality curves from heart failure the population in Bahia State, Brazil, by age groups Source: DATASUS and IBGE 


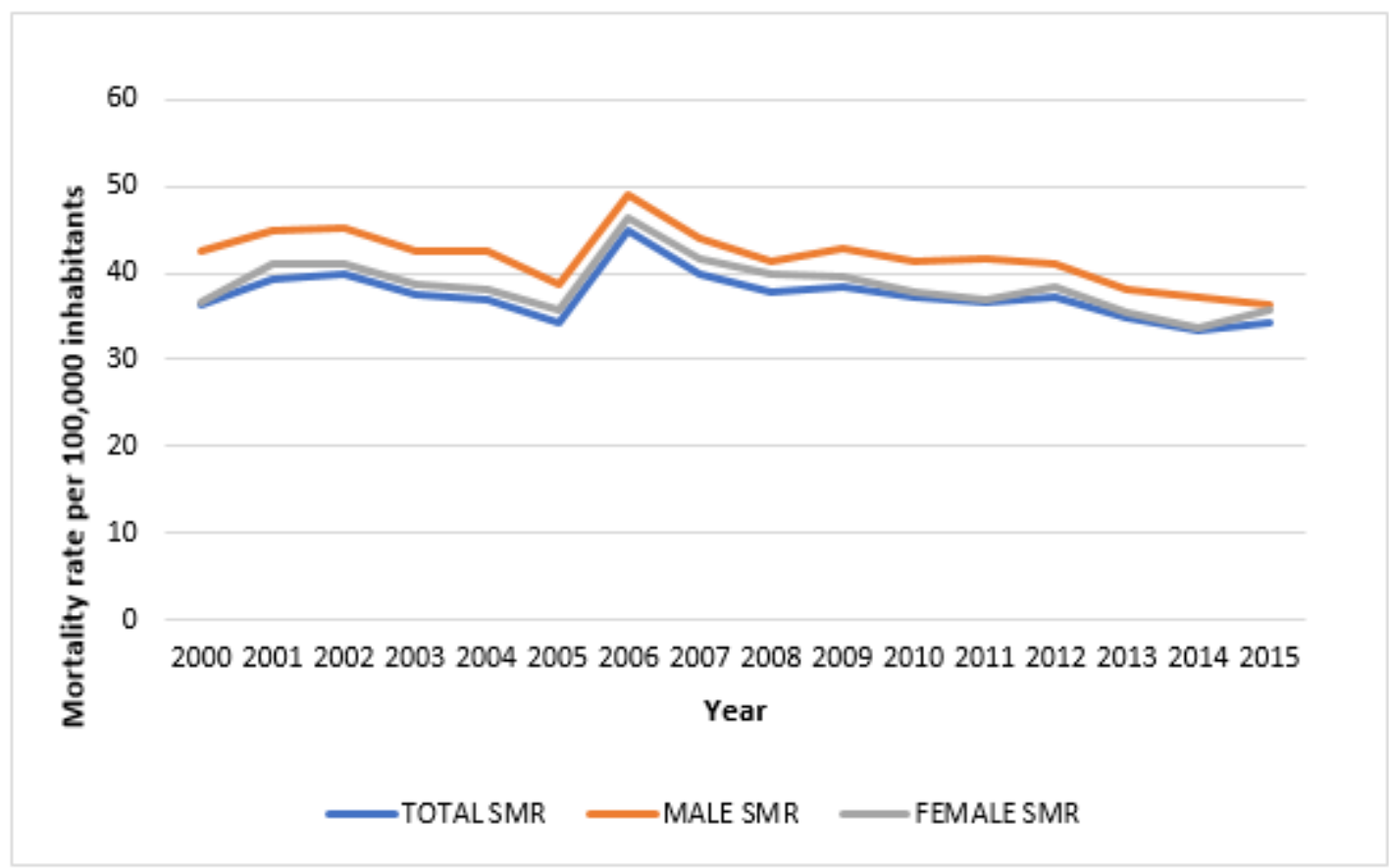

Figure 6 - Age-standardized mortality curves due to cerebrovascular diseases in the population of Bahia, Brazil; SMR: standardized mortality rate

\section{Discussion}

In the present study, trends in mortality from cardiovascular diseases in Bahia from 2000 and 2015 was described, to call attention to mortality patterns in a large state in the northeast of Brazil that differ from the south and southeast regions of the country. This may be related to socioeconomic and cultural inequalities, recognized in a continental country like Brazil. ${ }^{8-10}$ The study showed stable mortality rates from cardiovascular diseases in Bahia, after standardization by age, in total and female populations, with a small tendency for reduction in males, in the evaluated period. Analysis of mortality by age groups showed a trend towards an increase in mortality rates in the very old (over 80 years old) male and female populations.

Studies on cardiovascular disease mortality have demonstrated a decrease in the rates all over the world, especially in developed countries in Europe and North America. ${ }^{11-13}$ However, in one of these studies, Roth et al., ${ }^{12}$ assessing the correlation of epidemiological changes, population growth and aging with global mortality from cardiovascular disease in the period from 1990 to 2013, observed regional variations in relation to the studied factors, with a significant reduction in mortality only for the countries located in central or western Europe.

In Brazil, studies with similar methods to the present study showed a reduction in mortality from cardiovascular diseases. ${ }^{5,8,9}$ According to Brant et al., ${ }^{8}$ from 1990 to 2015, this decreasing trend was more pronounced in the states of the south and southeast regions and was smaller in the states of the north and northeast regions. Guimarães et al., ${ }^{9}$ and Mansur and Favarato, ${ }^{10}$ in studies that evaluated the trends in mortality from cardiovascular disease between 1980 and 2012, observed an increase in the rates only for the northeast region of Brazil. An analysis of the National Health Surveillance System showed a similar trend to that of the northeast region in the state of Bahia between 1996 and $2009 .{ }^{6}$

In relation to specific cardiovascular causes of mortality, there was a progressive increase in the crude and standardized (by age) mortality rates from ischemic heart disease in the period, which was justified by the increase in mortality in the population above 60 years 


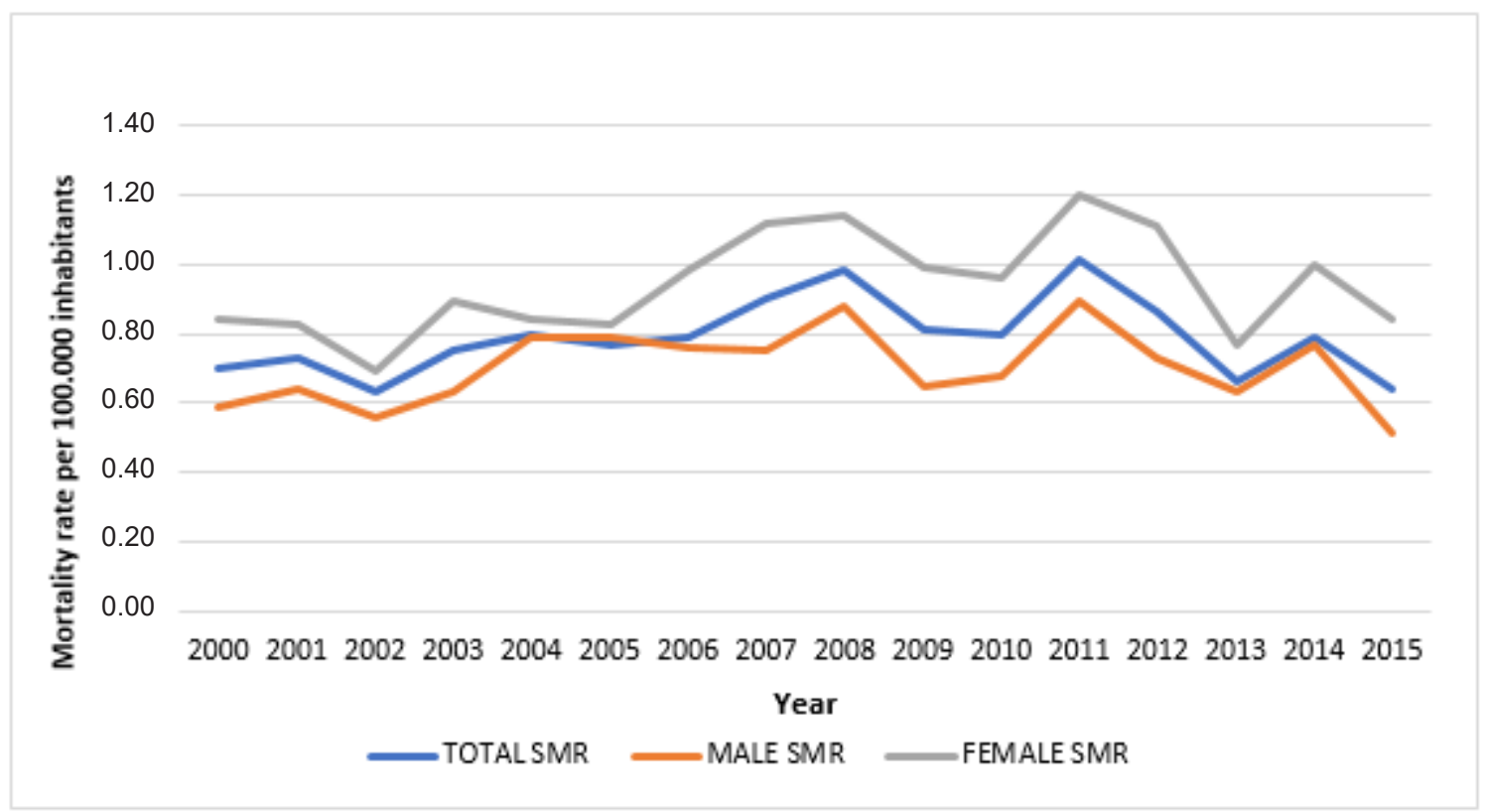

Figure 7 - Age-standardized mortality curves due to rheumatic heart disease in the population of Bahia, Brazil; SMR: standardized mortality rate.

Fonte: DATASUS e IBGE

of age. About heart failure, there was a reduction in crude and standardized mortality rates for the total, male and female populations during the study period. A reduction in standardized mortality rates was observed from cerebrovascular diseases in the total population, and in females and males. Finally, regarding rheumatic heart disease, while the crude mortality rates showed stability, the age-adjusted rates showed a slight decrease, progressive from 2008 on.

Roth et al., ${ }^{12}$ in a study on the main causal factors of the change in mortality between 1990 and 2013, pointed out that ischemic heart disease is the largest cause of death from cardiovascular diseases in several parts of the world. Despite this, they observed a significant decline in the mortality trends from this specific cause in most countries, as well as from cerebrovascular disease, heart failure and rheumatic heart disease. The same study showed a reduction in mortality from rheumatic heart disease worldwide in the period evaluated. ${ }^{12}$ On the other hand, in 2014, the annual epidemiological update on cardiovascular diseases of the European Society of Cardiology showed a trend to increase or slight decrease in mortality from ischemic heart disease in some European countries. ${ }^{13}$
Some Brazilian studies have evaluated the patterns of mortality from cardiovascular diseases in different periods and according to different specific causes. Mansur and Favarato, ${ }^{10}$ analyzing the mortality from cardiovascular disease in the five Brazilian regions from 1980 to 2012, observed a reduction in mortality rates from ischemic heart disease and cerebrovascular disease in the south and southeast regions, and an increase in these rates in the northeast region, in line with national studies that analyzed regional variations in mortality in the same period and between 1990 and 2015.,9 Gaui et al., ${ }^{14}$ in a study that evaluated mortality from two specific cardiovascular diseases between 1996 and 2011, found a decrease in standardized mortality rates from heart failure in all Brazilian regions. Brant et al., ${ }^{8}$ found a significant reduction in mortality rates from rheumatic heart disease between 1990 and 2015.

The increase in mortality from ischemic heart disease in Bahia observed in our study contrasts with other national and international studies. This may be explained by population aging and difficult treatment of several risk factors involved in the pathophysiology of atherosclerosis, such as dyslipidemia, smoking and 
diabetes, and consequently more serious or recurrent clinical manifestations of ischemic heart disease. ${ }^{5}$ In addition, regional variations in the management of acute ischemic syndromes may have contributed to the increase in mortality in Bahia, since studies revealed that the use of scientific evidence-based therapies in the treatment of patients with acute coronary syndromes seems to be below expectations in the northeast region, as is the case of myocardial reperfusion therapies (fibrinolytic therapy or primary percutaneous coronary intervention) for STelevation myocardial infarction. ${ }^{15,16}$

Regarding heart failure mortality observed in Bahia, there was a decreasing trend, which is in accordance with national and international scientific literature and can be justified, at least in part, by the expansion of available therapies proven to be effective in reducing case fatality rates among patients with heart failure, as is the case of beta blockers and renin-angiotensinaldosterone system inhibitors. ${ }^{14,17}$

The stabilization or slight reduction in mortality rates due to rheumatic heart disease was an expected finding, since, despite the inequalities, there was an improvement in social conditions, and in the access to health care and to penicillin as primary and secondary prophylaxis to rheumatic fever, favoring the prevention of late cardiac complications caused by the disease. ${ }^{18.19}$

The present study has limitations. First, as an analysis of aggregated data, the internal validity of the results depends on the reliability of the databases used in the search. Our sources were DATASUS (Mortality Information Service - SIM) and the IBGE. Mortality information obtained from SIM/DATASUS depends on the accuracy of death certificates, which is directly or indirectly influenced by the access to health services, ability of health units to establish etiological diagnosis, ability of professionals to fill out death declarations correctly, among others. Depending on the city, the reliability of primary and secondary causes of death may vary; errors in diagnosis and the use of signs and symptoms to establish the basic cause of death are more frequently in less-favored areas in terms of health care, which is the case of many locations in the state of Bahia. In addition, using only the primary cause of death as a data source may hide relevant information and cause underestimation in mortality rates due to a specific cause. ${ }^{5,9,10,20}$ However, DATASUS is a national reference source of information on mortality. Another limitation is the relatively short duration of the study (15 years); however, during this period, the 10th revision (ICD-10) was the only classification of diseases used in Brazil, preventing potential changes in the percentage of causes of deaths due to a shift in the diagnostic classification.

Despite these limitations, the present article contributes to the knowledge about cardiovascular mortality patterns in the state of Bahia, and provides important information for planning, management and development of health policies and actions.

\section{Conclusion}

The present study found that age-standardized mortality rates from cardiovascular disease remained stable in the state of Bahia between the years 2000 and 2015. Regarding specific causes of cardiovascular mortality, in contrast to other causes of death analyzed, there was an increase in the mortality rate from ischemic heart disease in the total population and by sex group, especially in the age groups above 60 years.

\section{Potential Conflict of Interest}

No potential conflict of interest relevant to this article was reported.

\section{Sources of Funding}

There were no external funding sources for this study.

\section{Study Association}

This article is part of the thesis of monography (course conclusion) submitted by Yana Mendonça Nascimento, from Universidade Federal da Bahia.

\section{Ethics Approval and Consent to Participate}

This article does not contain any studies with human participants or animals performed by any of the authors.

\section{Author Contributions}

Conception and design of the research: Nascimento YM, Latado AL. Acquisition of data: Nascimento YM, Latado AL. Analysis and interpretation of the data: Nascimento YM, Latado AL. Statistical analysis: Nascimento YM, Latado AL. Writing of the manuscript: Nascimento YM, Latado AL. Critical revision of the manuscript for intellectual content: Latado AL. 


\section{References}

1. Schmidt MI, Duncan BB, E Silva GA, Menezes AM, Monteiro CA, Barreto $\mathrm{SM}$, et al. Chronic non-communicable diseases in Brazil: Burden and current challenges. Lancet. 2011;377(9781):1949-61.

2. World Health Organization. (WHO). Noncommunicable diseases: progress monitor 2017. Geneva;2017.

3. Brasil. Ministério da Saúde. Secretaria de Vigilância em Saúde. Plano de ações estratégicas para o enfrentamento das doenças crônicas não transmissíveis (DCNT) no Brasil 2011-2022. Brasília; 2011

4. Instituto Brasileiro de Geografia e Estatística. (IBGE). Pesquisa Naciona de Saúde 2013 Rio de Janeiro: Instituto Brasileiro de Geografia e Estatística (IBGE); 2014.

5. Mansur A de P, Favarato D. Trends in Mortality Rate from Cardiovascular Disease in Brazil, 1980-2012. Arq Bras Cardiol. 2016;107(1):20-1.

6. Brasil. Ministério da Saúde; Secretaria de Vigilância em Saúde. Sistema Nacional de Vigilância em Saúde: relatório de situação: Brasilia;2011.

7. Instituto Brasileiro de Geografia e Estatística. (IBGE). Sinopse do Censo Demográfico 2010.Rio de Janeiro; 2019.

8. Brant LCC, Nascimento BR, Passos VMA, Duncan BB, Benseñor IJM, Malta DC, et al. Variations and particularities in cardiovascular disease mortality in Brazil and Brazilian states in 1990 and 2015: estimates from the Global Burden of Disease. Rev Bras Epidemiol. 2017;20(1Suppl 1):116-28

9. Guimarães RM, Andrade SSCA, Machado EL, Bahia CA, Oliveira MM, Jacques FVL. Diferenças regionais na transição da mortalidade por doenças cardiovasculares no Brasil, 1980 a 2012. Rev Panam Salud Publica. 2015;37(2):83-9.

10. Mansur AP, Favarato D. Mortalidade por Doenças Cardiovasculares em Mulheres e Homens nas cinco Regiões do Brasil, 1980-2012. Arq.Bras. Cardiol. 2016 [online] ahead of print.PP.0-0

11. Mozaffarian D, Benjamin EJ, Go AS, Arnett DK, Blaha MJ, Cushman M, et al; American Heart Association Statistics Committee and Stroke Statistics Subcommittee. Heart disease and stroke statistics-2015 update: a report from the American Heart Association. Circulation. 2015;131(4):e29-322. Errata in: Circulation. 2015;131(24):e535.
12. Roth GA, Forouzanfar MH, Moran AE, Barber R, Nguyen G, Feigin VL, et al. Demographic and epidemiologic drivers of global cardiovascular mortality. N Engl J Med. 2015;372(14):1333-41.

13. Nichols MS, Nichols M, Townsend N, Scarborough P, Rayner M. Cardiovascular disease in Europe 2014: epidemiological update. Eur Heart J. 2014;35(42):2950

14. Gaui EN, Oliveira GM, Klein CH. Mortality by heart failure and ischemic heart disease in Brazil from 1996 to 2011. Arq Bras Cardiol. 2014;102(6):557-65.

15. Baena CP, Chowdhury R, Schio NA, Sabbag AE Jr, Guarita-Souza LC, Olandoski M, et al. Ischaemic heart disease deaths in Brazil: current trends, regional disparities and future projections. Heart. 2013;99(18):1359-64.

16. Nicolau JC, Franken M, Lotufo PA, Carvalho AC, Marin Neto JA, Lima FG, et al. Use of demonstrably effective therapies in the treatment of acute coronary syndromes: comparison between different Brazilian regions. Analysis of the Brazilian Registry on Acute Coronary Syndromes (BRACE). Arq Bras Cardiol. 2012;98(4):282-9.

17. Rhode LEP, Montera MW, Bocchi EA, Clausell NO, Albuquerque DC, Rassi S, et al. Sociedade Brasileira de Cardiologia. Diretriz brasileira de insuficiência cardíaca crônica e aguda. Arq Bras Cardiol. 2018;111(3):436539.

18. Barbosa PJB, Müller RE, Latado AL, Achutti AC, Ramos AIO, Weksler C, et al. Diretrizes Brasileiras para Diagnóstico, Tratamento e Prevenção da Febre Reumática da Sociedade Brasileira de Cardiologia, da Sociedade Brasileira de Pediatria e da Sociedade Brasileira de Reumatologia. Arq Bras Cardiol. 2009;93(3 Supp 4):1-18.

19. Carapetis JR, Steer AC, Mulholland EK, Weber M. The global burden of group A streptococcal diseases. Lancet Infect Dis. 2005; 5 (11):685-94.

20. Centers for Disease Control and Prevention. Changes in mortality from heart failure - United States, 1980-1995. JAMA. 1998;280(10):874-5. 